\title{
Особенности химического состава воды и донных отложений малых арктических горных озер
}

Даувальтер В.А., Денисов Д.Б.

Институт проблем промышленной экологии Севера КНЦ РАН, Anamumbl,vladimir@inep.ksc.ru

Аннотация. Для горных арктических озер (высота уреза воды от 434 до 812 м н. у. м., Хибинский щелочной массив) получены данные о химическом составе вод и донных отложений, и на их основе проведена оценка современного состояния водосборного бассейна. Исследуемые озера характеризуются олиготрофным статусом и низкой минерализацией. Воды озер относятся к гидрокарбонатному классу и имеют нейтральные величины рН (кроме оз. Каровое). Особенностью химического состава воды исследуемых озер является повышенное относительное содержание катиона $\mathrm{K}^{+}$, который находится на втором месте после иона $\mathrm{Na}^{+}$. Показано, что в оз. Тахтаръявр, расположенном на юго-западном склоне Хибинского массива, четко выражены последствия аэротехногенного загрязнения. Аккумуляция тяжелых металлов $(\mathrm{Cu}, \mathrm{Ni}, \mathrm{Hg}$ и особенно $\mathrm{Pb}$ ) наблюдается в верхних слоях донных отложений (3-5 см) озер.

Ключевые слова: высокогорные арктические озера, Хибины, качество воды, донные отложения, тяжелые металлы.

\section{Features of chemical composition of water and sediments of small Arctic mountain lakes}

Dauvalter V.A., Denisov D.B.

Institute of North Industrial Ecology Problems KSC RAS, Apatity, vladimir@inep.ksc.ru

Abstract. Data on chemical composition of waters and sediments were obtained for mountain Arctic lakes (altitude above sea level from 434 to $812 \mathrm{~m}$, the Khibiny alkaline massif), the assessment of current state of a catchment basin is carried out on their basis. The studied lakes are characterized by the oligotrophic status and low mineralization. Lake waters belong to the hydrocarbonate class and have neutral $\mathrm{pH}$ values (except Lake Karovoye). A peculiav Feature of a chemical composition of water of the studied lakes is the raised relative contents of $\mathrm{K}^{+}$cation, which is at the second place after $\mathrm{Na}^{+}$ion. Consequences of air pollution are manifested in Lake Takhtarjavr located on the southwest slope of the Khibiny massif. Accumulation of heavy metals $(\mathrm{Cu}, \mathrm{Ni}, \mathrm{Hg}$ and particularly $\mathrm{Pb})$ is observed in the surface layers of lake sediments $(3-5 \mathrm{~cm})$.

Keywords: mountain Arctic lakes, Khibiny Mountains, water quality, sediments, heavy metals.

Малые горные арктические водоемы являются уникальным источником экологической информации о состоянии окружающей природной среды, антропогенном загрязнении, условиях формирования качества вод и широко используются в комплексном экологическом мониторинге и палеоэкологических исследованиях (Моисеенко и др., 1997; Денисов, 2012; Денисов и др., 2015). Эти озера представляют собой уникальные модельные объекты для оценки экологического состояния и степени антропогенного влияния на определенную территорию, потому что они характеризуются малой площадью водосбора, преобладанием атмосферного питания и коротким периодом открытой воды. Преимуществом исследований малых горных водоемов является возможность получения репрезентативных данных даже в результате однократного исследования.

В статье рассматриваются результаты изучения химического состава воды и донных отложений (ДО) высокогорных альпийских озер, расположенных на территории Хибинского щелочного горного массива (рис. 1). Питание исследуемых водоемов осуществляется за счет атмосферных осадков, за долгую зиму (8-9 месяцев) накапливающихся в виде снежников, иногда присутствующих на водосборе озер в течение всего года, например, на водосборе оз. Академическое. Почвенный покров на водосборах исследуемых озер выражен слабо. Растительность характеризуется преобладанием лишайников рода Certaria, встречаются представители семейств Vacciniaceae, Cyperaceae и другие типичные растения высокогорной тундры. Склоны берегов озер крутые, с каменными осыпями, скальными выступами, трещинами. Литоральная зона водоемов 


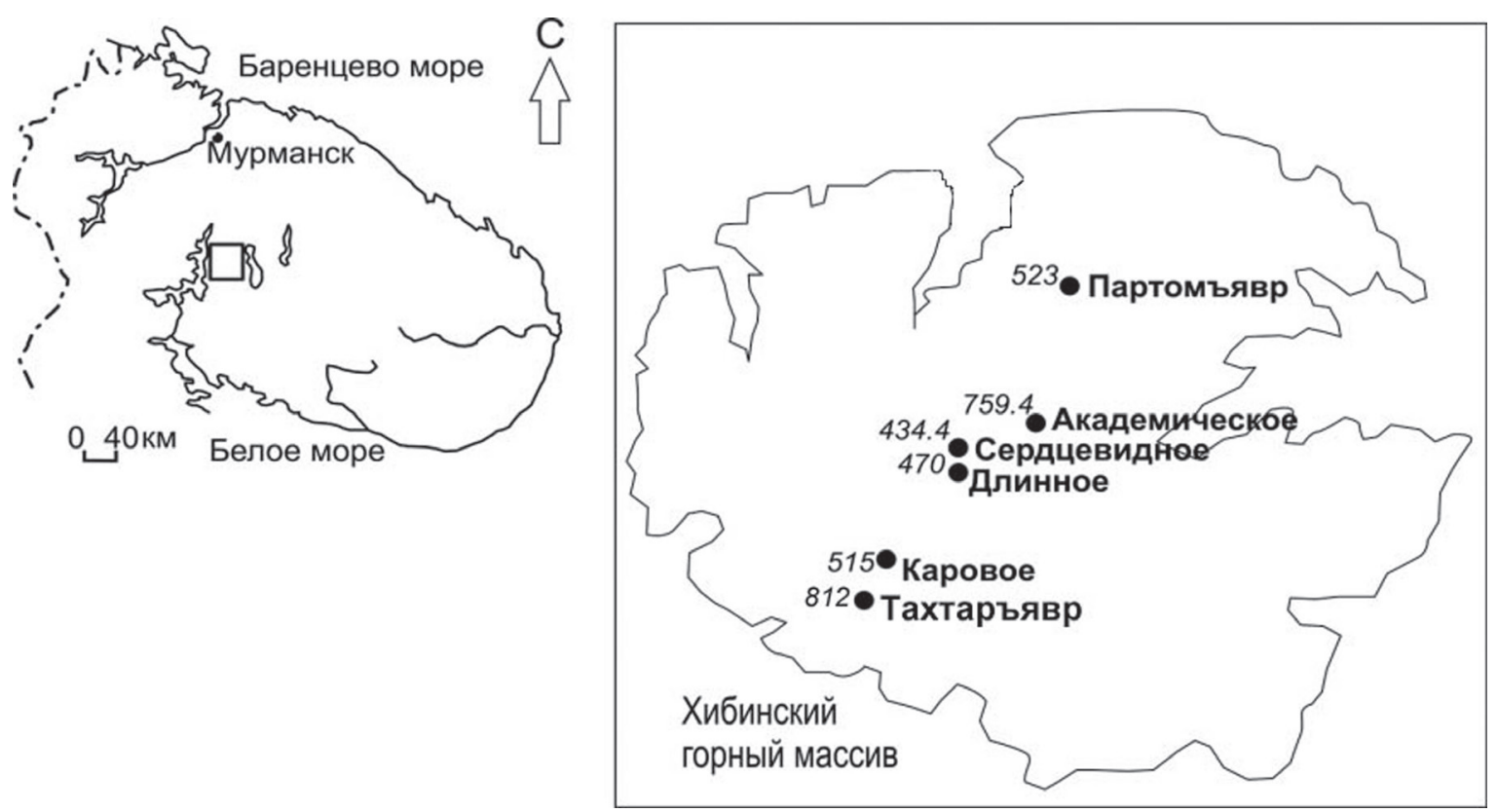

Рис. 1. Карта-схема расположения малых озер Хибинского горного массива и прилегающих территорий с указанием высоты над уровнем моря, м.

Fig. 1. Schematic map of arrangement of small lakes of the Khibiny massif and adjacent territories with the indication of altitude above sea level, $\mathrm{m}$.

каменистая, которая часто переходит в чашу озера с крутыми уклонами. Вода озер характеризуется малым содержанием взвешенных веществ, высокой прозрачностью и голубым цветом. Летом в озерах устанавливается температурная стратификация. Прямое антропогенное воздействие на водоемы в настоящее время не оказывается, рекреационная нагрузка также незначительна. Атмосферное питание озер определяет зависимость химического состава вод и ДО от природных особенностей водосбора и аэротехногенного загрязнения.

Качество вод исследованных озер соответствует естественно-природным водоемам Мурманской области, с низкими концентрациями биогенных элементов, общей минерализации и высоким содержанием кислорода (Кашулин и др., 2008). Некоторые основные гидрохимические показатели озер приведены в таблице 1-3. Величины рН близки к нейтральным значениям, что нетипично для озер Хибинского массива, воды которых находятся в тесном контакте с коренными щелочными горными породами, и относятся к слабощелочным и щелочным. Воды оз. Каровое по величине рН относятся к слабокислым, что характерно для вод атмосферных осадков (Даувальтер и др., 2008). Водоемы (за исключением оз. Каровое) способны противостоять кислотным выпадениям благодаря щелочному составу подстилающих горных пород, сравнительно высокой буферной емкости (больше критического значения 50 мкг-экв/л) и значительным глубинам. Это подтверждается невысокими концентрациями анионов сильных кислот $\mathrm{SO}_{4}{ }^{2-}, \mathrm{NO}_{3}^{-}$и околонейтральными значениями $\mathrm{pH}$. Воды исследованных озер относятся к гидрокарбонатному классу (кроме оз. Каровое) и натриевой группе. В воде оз. Каровое преобладающим анионом является сульфат-ион, минерализация воды очень низкая. Особенностью химического состава воды исследуемых озер является повышенное относительное содержание катиона $\mathrm{K}^{+}$, который находится на втором месте после иона $\mathrm{Na}^{+}$, тогда как равнинные озера Мурманской области, не получающие прямых стоков промышленных предприятий, характеризуются гидрокарбонатным классом и кальциевой группой, и катион $\mathrm{K}^{+}$стоит, как правило, на последнем месте среди основных катионов (Кашулин и др., 2008). По химическому составу вода оз. Каровое близка к составу атмосферных осадков, поэтому можно сделать вывод, что основное участие в питании озера принимают атмосферные осадки, главным образом, в твердом виде (снежники). Минерализация других исследованных озер также низкая; отмечается тенденция увеличения минерализации с уменьшением абсолютных отметок уреза воды в озерах $(\mathrm{r}=0.59)$. 
Таблица 1. Средние значения величины $\mathrm{pH}$, содержания главных ионов и минерализации (М) воды исследуемых озер (мг/л).

Table 1. Average values of $\mathrm{pH}$, the contents of the main ions and mineralization $(\mathrm{M})$ of water of the studied lakes $(\mathrm{mg})$.

\begin{tabular}{|l|c|c|c|c|c|c|c|c|c|}
\hline Озеро & $\mathrm{pH}$ & $\mathrm{Ca}^{2+}$ & $\mathrm{Mg}^{2+}$ & $\mathrm{Na}^{+}$ & $\mathrm{K}^{+}$ & $\mathrm{HCO}_{3}^{-}$ & $\mathrm{SO}_{4}^{2-}$ & $\mathrm{Cl}^{-}$ & $\mathrm{M}$ \\
\hline Тахтаръявр & 6.86 & 0.36 & 0.04 & 2.77 & 0.64 & 6.3 & 1.3 & 0.6 & 11.9 \\
\hline Академическое & 6.86 & 0.20 & 0.03 & 2.50 & 0.60 & 4.9 & 1.4 & 0.5 & 10.1 \\
\hline Каровое & 5.91 & 0.15 & 0.03 & 0.82 & 0.25 & 0.5 & 1.5 & 0.4 & 3.7 \\
\hline Партомъявр & 6.97 & 0.40 & 0.13 & 6.11 & 0.99 & 9.1 & 6.0 & 1.2 & 23.9 \\
\hline Длинное & 7.07 & 0.47 & 0.07 & 4.45 & 1.35 & 10.6 & 2.6 & 0.7 & 20.3 \\
\hline Сердцевидное & 7.28 & 0.56 & 0.07 & 6.33 & 1.74 & 15.5 & 3.1 & 0.6 & 27.9 \\
\hline
\end{tabular}

Таблица 2. Средние содержания соединений $\mathrm{N}$ и $\mathrm{P}\left(\right.$ мкг/л), цветности $\left({ }^{\circ} \mathrm{Pt}\right)$, химического потребления О, органического С и Si (мг/л) в воде исследуемых озер.

Table 2. Average contents of compounds of $\mathrm{N}$ and $\mathrm{P}(\mu \mathrm{g} / 1)$, color $\left({ }^{\circ} \mathrm{Pt}\right), \mathrm{COD}_{\mathrm{Mn}}$, TOC and $\mathrm{Si}(\mathrm{mg} / \mathrm{l})$ in water of the studied lakes.

\begin{tabular}{|l|c|c|c|c|c|c|c|c|c|}
\hline \multicolumn{1}{|c|}{ Озеро } & $\mathrm{NH}_{4}^{+}$ & $\mathrm{NO}_{3}^{-}$ & $\mathrm{N}_{\text {обш }}$ & $\mathrm{PO}_{4}^{3-}$ & $\mathrm{P}_{\text {обш }}$ & Цветн. & $\mathrm{XПК}_{\mathrm{Mn}}$ & $\mathrm{C}_{\text {орг }}$ & $\mathrm{Si}$ \\
\hline Тахтаръявр & 7 & 90 & 236 & 2 & 6 & 4 & 0.5 & 1.9 & 1.66 \\
\hline Академическое & 4 & 44 & 93 & $\mathrm{H.o.}$ & 3 & 5 & 0.6 & 2.0 & 1.30 \\
\hline Каровое & 6 & 2 & 152 & 1 & 3 & 5 & 0.6 & 2.0 & 0.37 \\
\hline Партомъявр & 26 & 161 & 277 & 2 & 5 & 5 & 0.3 & 1.8 & 2.31 \\
\hline Длинное & 11 & 65 & 172 & 1 & 4 & 7 & 0.5 & 2.0 & 1.45 \\
\hline Сердцевидное & 11 & 87 & 203 & 1 & 4 & 5 & 0.4 & 1.9 & 2.38 \\
\hline
\end{tabular}

Таблица 3. Средние содержания микроэлементов в воде исследуемых озер (мкг/л).

Table 3. The average contents of trace elements in water of the studied lakes $(\mu \mathrm{g} / 1)$.

\begin{tabular}{|l|c|c|c|c|c|c|c|c|c|}
\hline \multicolumn{1}{|c|}{ Озеро } & $\mathrm{Al}$ & $\mathrm{Fe}$ & $\mathrm{Cu}$ & $\mathrm{Ni}$ & $\mathrm{Co}$ & $\mathrm{Zn}$ & $\mathrm{Mn}$ & $\mathrm{Sr}$ & $\mathrm{Pb}$ \\
\hline Тахтаръявр & 24 & 7 & 0.6 & 0.6 & 0.3 & 1.8 & 5 & 43 & 0.10 \\
\hline Академическое & 19 & 5 & 0.7 & 0.5 & 0.1 & 0.9 & 0.6 & 3 & н.о. \\
\hline Каровое & 133 & 28 & 0.2 & 0.6 & 0.3 & 2.3 & 3 & 32 & 0.30 \\
\hline Партомъявр & 35 & 18 & 3.4 & 2.3 & 0.2 & 3.6 & 2 & 29 & 0.30 \\
\hline Длинное & 45 & 9 & 0.9 & 0.5 & 0.2 & 2.2 & 1 & 64 & 0.28 \\
\hline Сердцевидное & 56 & 10 & 0.4 & 0.5 & 0.2 & 1.9 & н.о. & 71 & 0.30 \\
\hline
\end{tabular}

По содержанию биогенных элементов исследуемые водоемы относятся к олиготрофным с признаками мезотрофного. Содержание общего фосфора соответствует олиготрофному статусу, а общего азота в воде озер Тахтаръявр и Партомъявр - нижней границе мезотрофного (Романенко и др., 1990). Наибольшие содержания соединений азота в озерах на абсолютных отметках менее 500 м связаны, скорее всего, с близким расположением рудников АО «Апатит» и выбросами в атмосферу продуктов взрывов при добыче апатитонефелиновых руд. Повышенные содержания соединений азота в воде оз. Татхтаръявр связаны, вероятно, с их поступлением с производственной пылью Второй апатитонефелиновой обогатительной фабрики (АНОФ-ІІ) и его хвостохранилища.

Содержание приоритетных загрязнителей аэротехногенного происхождения $(\mathrm{Cu}, \mathrm{Ni})$ в воде соответствует самому высокому I классу качества вод (Романенко и др., 1990). Максимальные содержания $\mathrm{Cu}, \mathrm{Ni}$ и $\mathrm{Zn}$ отмечены в воде оз. Партомъявр, находящегося ближе всех из исследуемых озер к комбинату «Североникель», выбросы которого беспрепятственно достигают водосбора озера. В других озерах концентрации ТМ меньше средних значений для малых озер восточной (фоновой) части Мурманской области (Kashulin et al., 2017). Хибинский массив является препятствием для атмосферных выбросов металлургического комбината, и они не достигают водосборов исследуемых озер. Концентрация элементов, являющихся загрязнителями среды в результате деятельности апатитонефелинового производства (Al и Sr), находится в пределах диапазона значений, характерных 

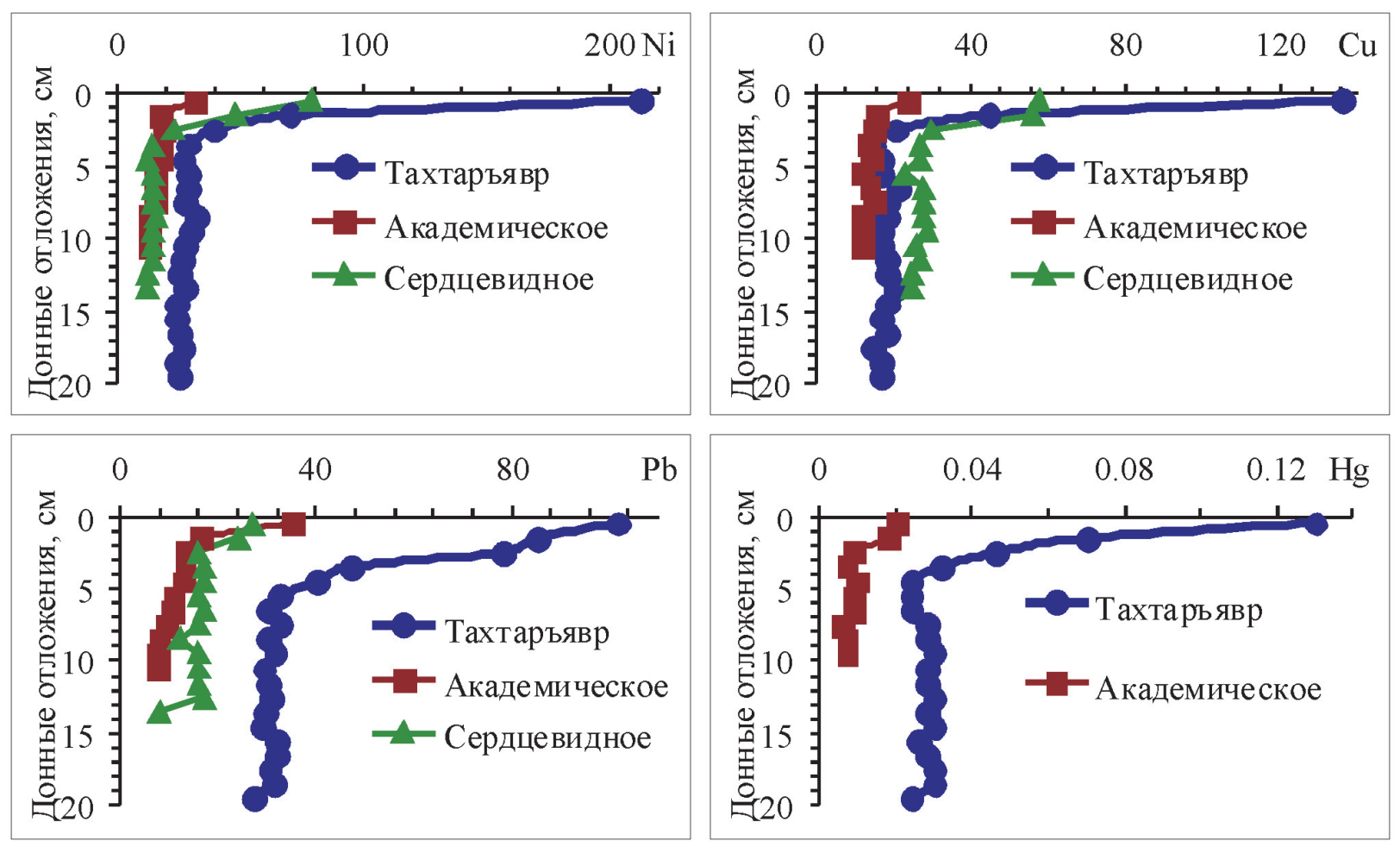

Рис. 2. Вертикальное распределение ТМ в ДО исследуемых озер (мкг/г сухого веса).

Fig. 2. Vertical distribution of heavy metals in sediments of the studied lakes ( $\mu \mathrm{g} / \mathrm{g}$ of dry weight).

для других малых озер Хибинского горного массива, куда не поступают стоки рудников (Кашулин и др., 2008). Наибольшие содержания $\mathrm{Al}$ и Fe зафиксированы оз. Каровое, что связано с низкими величинами $\mathrm{pH}$ в воде, при которых эти металлы приобретают большую миграционную способность (Никаноров, 2001). Это подтверждает также высокие отрицательные значения коэффициента корреляции величин $\mathrm{pH}$ с содержаниями $\mathrm{Al}$ и $\mathrm{Fe}(\mathrm{r}=-0.79$ и -0.78 соответственно). Наибольшие содержания $\mathrm{Sr}$ (также как и соединений азота) отмечены в воде озер, близко расположенных к предприятиям АО «Апатит», - Сердцевидное, Длинное и Тахтаръявр.

Характер распределения содержания ТМ в ДО свидетельствует о крайне низких скоростях осадконакопления в озерах (рис. 2). С учетом данных (Денисов, 2012; Даувальтер и др., 2015), особенностей рельефа и малой площади водосбора, а также в связи с незначительным поступлением аллохтонного вещества с территории водосборов, скорость накопления ДО может составлять доли мм в год. Аккумуляция некоторых $\mathrm{TM}(\mathrm{Cu}, \mathrm{Ni}, \mathrm{Hg}$ и особенно $\mathrm{Pb})$ наблюдается начиная с верхних слоев ДО (3-5 см) озер Татхтаръявр и Сердцевидное, что объясняется глобальным загрязнением атмосферы северо-запада Европы этими элементами в XIX-XX вв. Резкое увеличение содержания TM в поверхностном слое 0-2 см является результатом деятельности крупных металлургических комбинатов в Мурманской области в XX в. В оз. Академическое заметное увеличение содержаний ТМ отмечается только в поверхностном 1-см слое ДО, что говорит о незначительной скорости осадконакопления.

Коэффициенты загрязнения $\left(\mathrm{C}_{\mathrm{f}}\right.$ - отношение концентрации элемента в поверхностном 1-см слое ДО к содержанию этого элемента в самой нижней части колонки, определяемого как фоновое, Håkanson, 1980) для Cu и Ni наибольшие в оз. Тахтаръявр, и они относятся к высоким по классификации Л. Хокансона. В этом озере зафиксировано также максимальное загрязнение для $\mathrm{Hg}$, значительное по классификации Л.Хокансона. Максимальная величина $\mathrm{C}_{\mathrm{f}}$ по $\mathrm{Pb}$ (значительное по классификации Л.Хокансона) отмечена в оз. Академическое, хотя максимальная концентрация этого высокотоксичного ТМ зафиксирована в оз. Тахтаръявр (рис. 2, табл. 4). Наибольшее значение степени загрязнения $\mathrm{C}_{\mathrm{d}}$ (пограничное между значительным и высоким по классификации Л.Хокансона), рас- 
считанной как сумма коэффициентов загрязнения восьми ТМ (Cu, Ni, $\mathrm{Co}, \mathrm{Zn}, \mathrm{Cd}, \mathrm{Pb}, \mathrm{Hg}$ и $\mathrm{As})$, отмечено в оз. Тахтаръявр, расположенном на юго-западном склоне Хибинского массива, до которого беспрепятственно доходит аэротехногенное загрязнение комбината «Североникель» и АНОФ-ІІ. Озера Академическое и Сердцевидное также подвержены загрязнению, но меньшему, чем оз. Тахтаръявр, о чем свидетельствуют значения степени загрязнения, находящиеся на границе между умеренным и значительным согласно классификации Л.Хокансона.

Таблица 4. Концентрации ТМ в поверхностных (0-1 см) и фоновых слоях (вторая строка) ДО, значения коэффициентов $\left(\mathrm{C}_{\mathrm{f}}\right)$ и степени $\left(\mathrm{C}_{\mathrm{d}}\right)$ загрязнения исследуемых озер.

Table 4. Concentration of heavy metals in superficial $(0-1 \mathrm{~cm})$ and background layers (the second line) of sediments, values of factor $(\mathrm{Cf})$ and degree $(\mathrm{Cd})$ of contamination of the studied lakes.

\begin{tabular}{|c|c|c|c|c|c|c|c|c|c|c|c|}
\hline Озеро & Слой, см & ППП & $\mathrm{Cu}$ & $\mathrm{Ni}$ & $\mathrm{Zn}$ & Co & $\mathrm{Cd}$ & $\mathrm{Pb}$ & As & $\mathrm{Hg}$ & $\mathrm{C}_{\mathrm{d}}$ \\
\hline \multirow{3}{*}{ Тахтаръявр } & $0-1$ & 15.16 & 136 & 213 & 270 & 19.8 & 0.506 & 102 & 11.6 & 0.130 & - \\
\hline & $19-20$ & 16.89 & 17 & 25 & 390 & 16.6 & 0.196 & 27 & 9.62 & 0.024 & - \\
\hline & $\mathrm{C}_{\mathrm{f}}$ & & 8.1 & 8.4 & 0.7 & 1.2 & 2.6 & 3.7 & 1.2 & 5.4 & 31.4 \\
\hline \multirow{3}{*}{ Академическое } & $0-1$ & 24.68 & 24.1 & 31.6 & 103 & 5.44 & 0.94 & 35.1 & 3.32 & 0.020 & \\
\hline & $19-20$ & 24.97 & 12.0 & 12.5 & 51 & 5.16 & 0.58 & 7.3 & 2.37 & 0.007 & \\
\hline & $\mathrm{C}_{\mathrm{f}}$ & & 2.0 & 2.5 & 2.0 & 1.1 & 1.6 & 4.8 & 1.4 & 2.9 & 18.3 \\
\hline \multirow{3}{*}{ Сердцевидное } & $0-1$ & 22.90 & 58 & 79 & 122 & 7.0 & 1.19 & 27 & - & - & - \\
\hline & $13-14$ & 16.70 & 25 & 12 & 121 & 5.0 & 1.19 & 8 & - & - & - \\
\hline & $\mathrm{C}_{\mathrm{f}}$ & & 2.3 & 6.6 & 1.0 & 1.4 & 1.0 & 3.4 & - & - & 15.7 \\
\hline
\end{tabular}

Работа выполнена в рамках темы НИР №0226-2019-0045 и частично поддержана из средств гранта РФФИ (18-05-60125).

\section{Литература}

1. Даувальтер В.А., Даувальтер М.В., Салтан Н.В., Семенов Е.Н. Химический состав атмосферных выпадений в зоне влияния комбината «Североникель» // Геохимия. 2008. № 10. С. 1131-1136.

2. Даувальтер В.А., Кашулин Н.А., Денисов Д.Б. Тенденции изменения содержания тяжелых металлов в донных отложениях озер Севера Фенноскандии в последние столетия // Труды Карельского НЦ РАН. 2015. № 9. С. 62-75.

3. Денисов Д. Б. Реконструкция развития экосистемы малого горного субарктического водоема за последние 900 лет (на примере оз. Академическое, Хибины, Кольский полуостров) // Труды Кольского НЦ РАН. «Прикладная экология Севера». 2012. Вып. 1. С. 126-147.

4. Денисов Д.Б., Валькова С.А., Терентьев П.М., Черепанов А.А. Экологические особенности малых ледниковых субарктических озер (Хибинский горный массив, Кольский полуостров) // Труды Карельского научного центра РАН. 2015. № 2. С. 40-52.

5. Кашулин Н.А., Денисов Д.Б., Сандимиров С.С., Даувальтер В.А., Кашулина Т.Г., Малиновский Д.Н., Вандыш О.И., Ильяшук Б.П., Кудрявцева Л.П. Антропогенные изменения водных систем Хибинского горного массива (Мурманская область). В 2 т. Апатиты: Изд-во КНЦ РАН. 2008. Т. 1. 250 с., Т. 2. 282 с.

6. Моисеенко Т.И., Даувальтер В.А., Каган Л.Я. Горные озера как индикаторы загрязнения воздуха // Водные ресурсы. 1997. Т. 24. № 5. С. 600-608.

7. Никаноров А.М. Гидрохимия. СПб.: Гидрометеиздат, 2001. 444 с.

8. Романенко В.Д., Оксиюк О.П., Жукинский В.Н., Стольберг Ф.В., Лаврик В.И. Экологическая оценка воздействия гидротехнического строительства на водные объекты. Киев: Наук. думка. 1990. 256 с.

9. Håkanson L. An ecological risk index for aquatic pollution control - a sedimentological approach // Water Res. 1980. V. 14. P. $975-1001$.

10. Kashulin N.A., Dauvalter V.A., Denisov D.B., Valkova S.A., Vandysh O.I., Terentjev P.M., Kashulin A.N. Selected aspects of the current state of freshwater resources in the Murmansk Region, Russia // J. Environ. Science and Health, Part A. 2017. V. 52, No. 9. P. 921-929. 